ESPAÇO TEMÁTICO: VIOLÊNCIA, SAÚDE E CLASSES SOCIAIS

\title{
Trabalho e saúde-adoecimento de docentes em universidades públicas
}

\author{
Iana Vasconcelos ${ }^{1}$ \\ https://orcid.org/0000-0003-3049-0445 \\ Rita De Lourdes de Lima ${ }^{2}$ \\ https://orcid.org/0000-0002-7920-115X \\ ${ }^{1}$ Universidade do Estado do Rio Grande do Norte, Faculdade de Serviço Social, Mossoró, RN, Brasil \\ ${ }^{2}$ Universidade Federal do Rio Grande do Norte, Programa de Pós-Graduação em Serviço Social, Natal, RN, Brasil
}

\section{Trabalho e saúde-adoecimento de docentes em universidades públicas}

Resumo: Este artigo analisa os influxos do trabalho na saúde dos(as) docentes, com base em dados oriundos de pesquisa qualitativa, pautada no método crítico-dialético, cujo percurso metodológico incluiu revisão de literatura e pesquisa de campo realizada a partir de questionários e entrevistas semiestruturadas com 16 assistentes sociais docentes de universidades públicas do Rio Grande do Norte, do quadro permanente de programas de pós-graduação stricto sensu. Aborda, inicialmente, as determinações sociais da saúde com foco no trabalho; em seguida apresenta breve caracterização dos sujeitos; e, por fim, analisa a relação entre a situação concreta de vida e trabalho das entrevistadas e o processo de saúde-adoecimento. Os resultados apontam que as condições de trabalho docente nas universidades públicas são desgastantes e incidem no adoecimento destes(as) trabalhadores(as), embora, comumente, os nexos entre a vida laboral e a situação de saúde não estejam formalmente estabelecidos e registrados, e/ou nem sempre sejam visibilizados.

Palavras-chave: Trabalho. Saúde do trabalhador. Educação Superior.

\section{Work and health-illness of professors from public universities}

This article analyzes the inflows of the work in the health of the professors, based on data from qualitative research, based on the critical-dialectic method, whose methodological path included literature review and field research, carried out using questionnaires and semi-structured interview with 16 professors social workers from public universities in Rio Grande do Norte, from the permanent staff of stricto sensu postgraduate programs. Addresses, initially, the social determinations of health with a focus on work; then it presents a brief characterization of the subjects of the research; and, finally, it analyzes the relationship between the interviewees' life and work concrete situation and the health-illness process. The results show that the working conditions of the professors in public universities are exhausting and affect in the illness of these workers, although, commonly, the links between working life and the health situation are not formally established and registered, and / or they are not always made visible.

Keywords: Job. Worker's health. College education.

Recebido em 10.11.2020. Aprovado em 15.12.2020. Revisado em 13.02.2021.

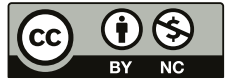

Este é um artigo publicado em acesso aberto (Open Access) sob a licença Creative Commons Attribution NonCommercial, que permite uso, distribuição e reprodução em qualquer meio, sem restrições desde que sem fins comerciais e que o trabalho original seja corretamente citado. 


\section{Introdução}

A saúde do trabalhador e da trabalhadora se configura importante objeto de estudo e de intervenção, em decorrência das evidências do desgaste na saúde (física e psíquica) relacionado ao trabalho, adensadas na atual conjuntura ${ }^{1}$. Os(as) trabalhadores(as) das Instituições de Ensino Superior (IES) públicas comumente se deparam com elevadas demandas de trabalho, o que tem desencadeado agravos à saúde destes(as) trabalhadores(as), expandindo-se, portanto, a necessidade de se estudar e intervir em aspectos relacionados à saúde de docentes.

Este artigo apresenta os resultados da pesquisa realizada no âmbito do Estágio Pós-doutoral realizado na Universidade Federal do Rio Grande do Norte, cujo objetivo foi analisar a relação entre trabalho e saúdeadoecimento de docentes de universidades públicas do Rio Grande do Norte (RN). Realizou-se uma pesquisa qualitativa, pautada no materialismo histórico-dialético, cujo percurso metodológico incluiu revisão de literatura e pesquisa de campo, efetivada por meio da aplicação de questionários e entrevistas semiestruturadas com assistentes sociais docentes do quadro permanente dos programas de pós-graduação stricto sensu na área do Serviço Social da Universidade Federal do Rio Grande do Norte (UFRN) e da Universidade do Estado do Rio Grande do Norte (UERN).

A pesquisa de campo foi realizada no período de abril a junho de 2019, contando com a participação de 16 professoras (sete docentes da UFRN e nove da UERN). Ressalte-se que na UFRN 19 docentes participavam desse programa, sendo 15 na condição de permanente. Entre esses(as), nove assistentes sociais. Por sua vez, o Programa de Pós-Graduação em Serviço Social e Direitos Sociais (PPGSSDS) da UERN é constituído por 14 docentes, sendo 11 assistentes sociais pertencentes ao quadro permanente.

Os dados foram interpretados recorrendo-se à técnica de análise de conteúdo (BARDIN, 2011). A investigação foi efetivada em consonância com os princípios expressos no código de ética do(a) assistente social e as indicações contidas na Resolução no 510/2016 do Conselho Nacional de Saúde².

Conforme assinalamos, no atual contexto, os(as) trabalhadores(as) das Instituições de Ensino Superior (IES) públicas vêm se deparando com condições de trabalho precárias e, ao mesmo tempo, com elevadas e diversificadas demandas de trabalho. O cotidiano de trabalho nas IES exige lidar com prazos exíguos, concorrer a editais de financiamento para custear atividades de pesquisa e/ou extensão, ministrar aulas, orientar a elaboração de trabalhos acadêmicos, avaliar provas e trabalhos, redigir relatórios, organizar/participar de eventos, além de proferir palestras e produzir/publicar livros e/ou artigos científicos, podendo, ainda, incluir funções de gestão. Em decorrência da intensificação crescente do trabalho e subsequente redução, ou mesmo supressão, da fronteira entre vida acadêmica e pessoal ocorrem prejuízos à saúde de muitos(as) destes(as) trabalhadores(as) (LEITE, 2015).

Para apresentar os resultados da pesquisa, além da introdução e considerações finais, o artigo encontrase estruturado do seguinte modo: inicialmente realiza uma discussão sobre as determinações sociais da saúde com foco na análise da incidência do trabalho no processo de saúde-adoecimento do(a) trabalhador(a), já apresentando alguns elementos sobre a realidade do trabalho nas universidades públicas brasileiras. Em seguida apresenta uma breve caracterização dos sujeitos da pesquisa com seu perfil e seus hábitos de vida e trabalho, traçando considerações sobre a relação entre esses elementos e o processo de saúde-doença. Por fim, no último item, apresenta parte das falas dos sujeitos e, partindo de uma perspectiva de totalidade, analisa a relação entre os determinantes sociais que incidem nas IES, a situação concreta de vida e trabalho dos(as) docentes entrevistados(as) e o processo de saúde-adoecimento desses sujeitos.

\section{As determinações sociais da saúde: uma análise com ênfase no trabalho}

A saúde-adoecimento dos seres humanos expressa suas condições de vida no que concerne à alimentação, moradia, educação, saneamento, meio ambiente, trabalho, renda, atividade física, transporte, lazer e outros aspectos relativos ao acesso a bens e serviços socialmente produzidos (BRASIL, 1990). Tais elementos, por sua vez, são determinados pela forma de organização das relações sociais que, na sociedade capitalista fundada na desigualdade e na exploração da classe trabalhadora - , se caracteriza pela negação, para um grande contingente da população, de condições necessárias a uma vida saudável. Nessa perspectiva, pautado no reconhecimento das determinações sociais da saúde, este estudo prioriza o trabalho, por conceber, consoante 
à produção teórica marxiana e marxista, seu caráter fundante do ser social e ineliminável da vida humana ${ }^{3}$. Ao mesmo tempo, na sociedade capitalista, alicerçada na produção de mercadorias com vistas à acumulação de capital, o trabalho ocorre com base na exploração e se torna fonte de alienação e desgaste do(a) trabalhador(a $)^{4}$.

Acerca das determinações sociais da saúde e sua relação com a sociedade de classes, Albuquerque e Silva (2014, p. 961-962) esclarecem:

[...] em uma sociedade de classes, em um mesmo momento histórico, o modo de viver, adoecer e morrer das diferentes classes e estratos de classe é bastante diverso. Em uma sociedade como a brasileira, por exemplo, já se sabe do que mais adoecem e morrem os médicos, os bancários, os banqueiros, os pedreiros, os engenheiros, os estivadores, os trabalhadores de telemarketing, os desempregados, entre outros. Têm uma expectativa de vida bastante diversa e adoecem e morrem por causas bastante distintas devido ao modo como se inserem no mundo da produção e no consumo.

É importante ressalvar que, segundo Antunes e Praun (2015, p. 410), "os acidentes de trabalho e as manifestações de adoecimento com nexo laboral não são fenômenos novos, mas processos tão antigos quanto a submissão do trabalho às diferentes formas de exploração". Na atual conjuntura, o caráter desgastante do trabalho se intensifica com a reestruturação capitalista, da qual fazem parte as medidas estatais pautadas no ideário neoliberal ${ }^{5}$, que acentuam sua funcionalidade na reprodução do capital em detrimento dos direitos dos(as) trabalhadores(as). Concomitantemente, intensificam-se medidas de redução dos custos com a força de trabalho, com consequente aumento do desemprego e do domínio do tempo de trabalho, o que converte, intensificadamente, o ambiente de trabalho em espaço adoecedor. De tal modo, nesta busca incessante e insaciável de reduzir o tempo de trabalho necessário e ampliar a parcela do excedente, várias iniciativas são implementadas, dentre as quais se destacam: a flexibilização/terceirização dos contratos, a gestão por metas de produtividade ${ }^{6}$, a prática do assédio moral, dentre outros aspectos que disseminam o individualismo e a competitividade e fragilizam os laços de solidariedade entre os(as) trabalhadores(as), tornando-se mais um fator preditivo de adoecimento no trabalho (ANTUNES; PRAUN, 2015).

Estas circunstâncias extrapolam o âmbito da produção material e se espraiam nas diversas áreas de trabalho. Desse modo, estas tendências do mundo trabalho, ainda que gestadas na fábrica e amplamente praticadas no setor privado, acabam sendo incorporadas, mantidas algumas peculiaridades, no setor público, inclusive nas instituições de ensino. Nesse contexto, os(as) docentes das universidades públicas brasileiras se deparam com adversidades em suas condições de trabalho, concomitante a elevadas exigências de produtividade, o que acarreta sobrecarga de trabalho (extensas e intensas jornadas) e tende a elevar a suscetibilidade destes(as) ao adoecimento, inclusive no âmbito psicológico. Conforme Forattini e Lucena (2015, p. 34):

À docência de nível superior em uma IFES são atribuídas as atividades de ensino, pesquisa e extensão, além de funções administrativas. Cada um desses segmentos é composto de um conjunto de atividades altamente complexas que exigem atualizações constante do docente, tanto genéricas quanto específicas. Da pressão constante sobre o docente, advinda dos processos de qualificação, carreira, geração de resultados, do convívio com discentes que apresentam os mais variados níveis de cognição, da obediência às políticas públicas de ensino que privilegiam a burocracia e, principalmente, da carga de trabalho excessiva e sem reconhecimento ou recompensas, advém um significativo impacto em sua estrutura psíquica.

Assim, as IES públicas brasileiras têm sido submetidas à lógica do mercado, com fortes rebatimentos na precarização e intensificação do trabalho docente, trazendo impactos nefastos à saúde destes(as) trabalhadores(as) e também na qualidade do seu trabalho, pois, conforme Lima (2016, p. 271), “[...] conhecimento crítico e autônomo só se constrói com tempo e recursos e, nesse sentido, não se concebe uma formação de ensino superior submetida a lógica do custo-benefício, da competividade e do aligeiramento e que é obrigada a mendigar recursos para suas pesquisas no mercado".

Nessa perspectiva, pautado no reconhecimento das determinações sociais da saúde, apresentamos em seguida uma breve caracterização das instituições e sujeitos que fizeram parte da pesquisa. 


\section{Quem são e o que fazem as docentes das universidades públicas do RN?}

Como já assinalamos, a pesquisa abrangeu dois programas de pós-graduação stricto sensu, sendo um na Universidade Federal do Rio Grande do Norte, situada em Natal, capital do Estado e outro na Universidade do Estado do Rio Grande do Norte, com sede em Mossoró, cidade do interior, e consistiu em revisão de literatura e aplicação de questionários e entrevistas semiestruturadas com 16 docentes dos dois programas. O primeiro programa foi criado no ano 2000, inicialmente com o curso de mestrado acadêmico e a partir de 2016 passou a oferecer também o doutorado, que no período da pesquisa (dez/2019) contava com 38 estudantes. O segundo programa foi criado mais recentemente, em 2014, com o curso de mestrado acadêmico, estando naquele momento (dez/2019) com 34 mestrandos(as).

Todas as participantes são mulheres, doutoras, com contratos efetivos (sete na UFRN e nove na UERN) e jornada de 40 horas com dedicação exclusiva. Cinco participantes informaram estar em cargos administrativos no momento da pesquisa (chefia do departamento, direção da faculdade e coordenação de programa de pós-graduação). Dentre as docentes entrevistadas, duas recebem bolsas de produtividade em pesquisa, pelo Conselho Nacional de Desenvolvimento Científico e Tecnológico (CNPq). O Quadro 1 apresenta uma síntese das principais informações colhidas nos questionários aplicados.

\section{Quadro 1 - Perfil das docentes}

\begin{tabular}{|c|c|c|c|c|c|c|c|}
\hline \multicolumn{8}{|c|}{ Docentes Doutoras assistentes sociais UFRN e UERN } \\
\hline \multirow[t]{2}{*}{ Raça/etnia } & \multicolumn{4}{|c|}{ Pretas e pardas } & & \multicolumn{2}{|c|}{ Brancas } \\
\hline & \multicolumn{4}{|c|}{10} & & \multicolumn{2}{|c|}{6} \\
\hline \multirow[t]{2}{*}{ Orientação sexual } & \multicolumn{4}{|c|}{ Heterossexual } & & \multicolumn{2}{|c|}{ Homossexual } \\
\hline & \multicolumn{4}{|c|}{11} & & \multicolumn{2}{|c|}{5} \\
\hline \multirow[t]{2}{*}{ Estado Civil } & \multicolumn{4}{|c|}{ Casada ou união estável } & & \multicolumn{2}{|c|}{ Solteiras } \\
\hline & \multicolumn{4}{|c|}{12} & & \multicolumn{2}{|c|}{4} \\
\hline \multirow[t]{2}{*}{ Tipo de alimentação } & \multicolumn{4}{|c|}{ Saudável } & & \multicolumn{2}{|c|}{ Não saudável } \\
\hline & \multicolumn{4}{|c|}{13} & & \multicolumn{2}{|c|}{3} \\
\hline \multirow[t]{2}{*}{ Faixa Etária } & \multicolumn{3}{|c|}{41 a 50 anos } & \multicolumn{2}{|c|}{51 a 60 anos } & \multicolumn{2}{|c|}{ Outros } \\
\hline & \multicolumn{3}{|l|}{8} & \multicolumn{2}{|c|}{6} & \multicolumn{2}{|r|}{2} \\
\hline \multirow[t]{2}{*}{ Religião } & \multicolumn{3}{|c|}{ Sem religião } & \multicolumn{2}{|c|}{ Espírita } & \multicolumn{2}{|c|}{ Católica } \\
\hline & \multicolumn{3}{|l|}{10} & & & & 2 \\
\hline Tempo de trabalho & Mais de 30 a & & & & & & 20 anos \\
\hline & 4 & & & & & & 6 \\
\hline Qualidade do sono & Muito Bom/ & & & & & & Ruim \\
\hline & 6 & & & & & & 3 \\
\hline $\begin{array}{l}\text { Frequência de } \\
\text { atividade física }\end{array}$ & $\begin{array}{c}\text { Duas a cinco veze } \\
\text { semanais }\end{array}$ & & Irregul & & & & Não informou \\
\hline & 8 & & & & & & 1 \\
\hline Frequência de lazer & Semanal & & & & & & Não informou \\
\hline & 9 & & & & & & 4 \\
\hline $\begin{array}{l}\text { Consumo de bebidas } \\
\text { alcóolicas }\end{array}$ & $\begin{array}{l}\text { Semanal (fins de } \\
\text { semana) }\end{array}$ & & $\begin{array}{l}\text { nal ou } \\
\text { isal }\end{array}$ & & & Rara & Nunca \\
\hline & 6 & & & & & & 4 \\
\hline
\end{tabular}

Fonte: Elaborado pelas autoras a partir dos dados da pesquisa (2020). 
De uma forma geral, a maioria tem filho(s) (nove), nenhuma é fumante, dormindo em média 6h57min diárias, de modo que a mínima duração diária de sono citada foi de 4 horas e a máxima entre 8 e 10 horas.

Apesar do sono regular, da maioria se exercitar e ter bons hábitos alimentares e de lazer, 11 delas registraram ter algum problema de saúde diagnosticado e fazer uso contínuo de alguma medicação para controle deste, dentre as quais, quatro apontaram mais de um problema associado, de forma que foram registradas as seguintes ocorrências: hipertensão (seis); tendência a artrose/artrose leve (duas); diabetes/pré-diabetes (duas); ansiedade (uma); depressão (uma); alergias (uma); hipertireoidismo (uma); labirintite (uma); enxaqueca (uma); obesidade (uma); problema de circulação/coagulação sanguínea (uma); doença renal (uma); problema na coluna (uma).

Quase todas costumam fazer exames e consultas regularmente, com periodicidade semestral ou anual (14), enquanto duas informaram que somente procuram um serviço de saúde em caso de adoecimento e uma destas comentou que acaba não priorizando isso. Mesmo entre as que afirmaram realizar acompanhamento médico periódico, uma delas evidenciou que as vezes isso acaba sendo protelado em função da prioridade atribuída às demandas de trabalho. Nos termos dessa docente:

Às vezes, assim... [...] tem consulta marcada (mesmo que seja pra fazer prevenção, né, que é o check-up anual), eu faço, mas eu remarco muitas vezes. Muitas vezes! [...]. Eu, geralmente eu desmarco, eu remarco e aí isso acaba não sendo prioridade entendeu? Eu tenho uma consulta marcada, tem um problema no departamento que tem que marcar uma reunião, eu cancelo. Eu ligo lá, aviso, transfiro. Se for olhar minha agenda... (risos) e vai ficando e vai ficando... né? (entrevista 6).

Compreendemos que a análise acerca do trabalho docente e seus possíveis influxos na saúde destes(as) trabalhadores(as), requer vislumbrá-lo em sua relação com a totalidade da vida social, bem como exige considerar aspectos relacionados às condições de vida destes sujeitos. Vale ressalvar, contudo, que neste estudo, considerando a área de formação profissional das pesquisadoras, não se propõe a abordar os aspectos biológicos e psicológicos da saúde-doença, priorizando as condições de trabalho, vida e lazer, embora reconheçamos que todas as dimensões são indissociáveis e que outros aspectos também são fundamentais para o desvelamento dos processos de saúde-adoecimento dos sujeitos.

\section{Interfaces entre trabalho e saúde-adoecimento na vida docente}

Foram relatados vários problemas de saúde entre as docentes que participaram da nossa pesquisa. $\mathrm{O}$ índice registrado $(68,7 \%)$ foi maior, inclusive, do que apontado em outro estudo realizado por Lima (2016) com professores(as) dos cursos de Serviço Social brasileiros, predominantemente vinculados(as) a instituições públicas federais e estaduais, o qual evidenciou que $44,6 \%$ desses(as) apresentavam problemas de saúde que exigem tratamento regular, tais como: problemas respiratórios; problemas ósseos; diabetes e hipertensão; ansiedade, fobias, depressão e doenças psicossomáticas em geral.

Indagadas acerca dos influxos do trabalho na sua condição de saúde-adoecimento, todas afirmaram que existe esta relação, sendo destacado por algumas que o desgaste oriundo da vida laboral afeta o conjunto dos(as) docentes e demais trabalhadores(as).

Sem dúvida alguma, o trabalho influencia na saúde do indivíduo e comigo não seria diferente. Na verdade, o trabalho na sociabilidade vigente é adoecedor. No cenário de exigência exagerada por bater metas e alcançar patamares surreais de produção, o trabalho adoece. A Universidade não está imune a isso. Embora estejamos, em algumas áreas como o próprio Serviço Social, refletindo criticamente sobre esses aspectos, não estamos imunes. (entrevista 10).

Foi ressalvado que tal adoecimento não se vincula exclusivamente ao trabalho. Esse registro é importante, pois, de fato, não se pode desconsiderar outras dimensões relativas às condições de vida, fatores genéticos e características individuais dos sujeitos.

[...] Se nós pensarmos bem, a maior parte da nossa vida nós passamos dentro do trabalho. Então, muito provavelmente, a grande maioria dos nossos problemas são advindos desse espaço né? Os nossos problemas, as nossas dificuldades, as nossas preocupações, a grande maioria delas. Claro que não estou retirando 
que nós temos preocupações com filho, nós temos preocupações com casa, nós temos preocupações com relacionamentos, que acho que são espaços extremamente importantes na nossa vida. Mas o trabalho, ele ocupa um espaço muito grande na nossa vida e é um espaço que nos traz inúmeras preocupações, inúmeros desgastes, inúmeras dificuldades. E quando nós temos esse espaço que não funciona bem, o nosso corpo vai responder e a nossa mente também. Então, muitos adoecimentos são advindos do trabalho e muitas vezes a gente é incapaz de perceber isso. (entrevista 5).

Foi realçado, de forma veemente, que o trabalho ocupa um lugar muito grande na vida dos(as) docentes e que sua influência na saúde é significativa, embora esta relação não se dê de imediato ou de forma tão visível. De tal modo, várias entrevistadas afirmaram já terem sido acometidas por problemas de saúde que consideram conectados (em alguma medida) com o trabalho que desenvolvem (11), dentre os quais foram citados: depressão, ansiedade, doença do pânico, labirintite, doenças cardiovasculares, obesidade, cansaço emocional/exaustão. Vejamos alguns relatos:

Com relação ao meu processo de adoecimento [...] eu comecei a perceber que eu não estava mais dentro do ritmo dessa lógica produtivista da universidade. [...] Olhe, eu estou de um jeito que eu não acho que é mais... não é só o ritmo de trabalho, é o tempo que eu já dediquei. Sabe quando você tá num relacionamento ou em algo que você não aguenta mais, que você quer parar? Eu estou desse jeito. [...] Porque hoje, você pode acreditar, vir pra universidade pra mim é terrível. Meu corpo todo nega isso daqui. (entrevista 14).

As vezes que eu me afastei, assim... por exemplo, durante períodos que eu me afastei de licença prêmio, eu melhorei né? [...] eu acho que os meus problemas de saúde principalmente a depressão, que eu vivenciei e estou em processo de tratamento... já faz mais de quatro anos (porque eu iniciei um tratamento e não melhorei, aí tive que iniciar outro, então já faz mais de quatro anos). Então, esse processo de tratamento ele foi disso né, desse... dessa coisa, de você terminar um doutorado, vir de uma sobrecarga intelectual que é o doutorado que você vive uma pressão muito grande e você volta pra universidade e você vive outras pressões que é a pressão de você publicar, de você assumir atividades docentes que você não assumia antes, como a pós-graduação [...]. (entrevista 4).

Um aspecto destacado por algumas docentes como indutor de maior sobrecarga, desgaste e adoecimento, é o envolvimento em funções de gestão e a inserção em programas de pós-graduação, já que, em geral, tais atividades se somam às anteriormente assumidas na graduação, além de elevarem as exigências de produtividade. De acordo com Forattini e Lucena (2015, p. 44):

Os critérios produtivistas impostos à conceituação de cursos Stricto Sensu, exigência de publicação em periódicos científicos nacionais e internacionais definidos por critérios do "Qualis", pressões em termos da produção científica de alunos, entre outros, acabam por intensificar o trabalho dos professores, consumindo-os em todo o seu período vital. A inspiração toyotista imposta pelos critérios de obtenção da mais valia absoluta e relativa expressas pela ocupação das vinte e quatro horas do tempo do trabalhador são retomados no ambiente acadêmico.

É importante ressaltar que uma das docentes que disse ter sua saúde afetada por questões atinentes ao trabalho, esclareceu as contradições deste processo, haja vista que sua relação com o trabalho também é prazerosa, pois possui identidade com a docência.

[...] eu tenho uma relação com o trabalho contraditória. Meu trabalho é identidade. Não é só detestável ou que me mata ou que me adoece entendeu? Não é! Eu estaria sendo absolutamente... não verdadeira, se eu dissesse isso. Muitas vezes eu saio da sala de aula de olho brilhando, entendeu? [...]. Mas o que mais hoje me... essa coisa da saúde, é assim... é o tempo, o tempo do trabalho ele é muito invasivo. (entrevista 15).

Em relação ao demasiado tempo destinado ao trabalho pelos(as) docentes de uma universidade pública brasileira, Queiróz e Emiliano (2020, p. 693) destacam:

A demanda de trabalho vem capturando seus espaços de descanso e impactando diretamente em suas necessidades básicas de saúde durante seu cotidiano de trabalho. Evidencia-se um vazamento no qual a 
organização de trabalho fundamentada sob extensas atividades parece ocupar o dia, a noite e a madrugada dos docentes. [...] Trata-se da contaminação da hora de não trabalho pelo trabalho.

Embora a grande maioria das entrevistadas (15) desconheçam se os adoecimentos dos(as) outros(as) docentes têm vínculos com o trabalho ${ }^{7}$, nas falas é perceptível a magnitude do problema e a grande ocorrência de doenças entre os(as) professores(as) com quem convivem.

O nível de adoecimento é alto e tem muitas pessoas adoecidas há muito tempo [estrala os dedos várias vezes], que você vê que precisa de uma terapia, de uma atividade física, né? Então, eu acho que... talvez o trabalho tenha um lugar muito grande na vida, às vezes. O lugar que este trabalho ocupa e as demandas que chegam. Então, a gente é tentada a responder né? (entrevista 8).

No tocante à (in)existência de diagnóstico que ateste o nexo entre o adoecimento e o trabalho docente, é elucidativa a fala de uma professora:

Eu cheguei um dia numa consulta e falei para o psiquiatra que era do trabalho. Eu disse: quando me afasto eu melhoro e quando eu retorno eu sinto, assim, aquele peso né, da responsabilidade das coisas. [...] E, assim, quando tem um feriado grande que eu fico em casa, mesmo fazendo algumas atividades, mas eu percebo que eu melhoro muito e no dia que vai começar a trabalhar, aí eu já sinto assim: ai meu Deus! [...] Eu disse a ele que aqui... a universidade me fazia mal. Eu que disse a ele. Ele não diagnosticou isso, eu que falei. (entrevista 4).

É importante ressalvar que este processo de adoecimento muitas vezes ocorre lenta e silenciosamente, de tal maneira que Seligmann-Silva (2011) considera difícil captar os perfis epidemiológicos de alguns processos de desgaste da saúde, por não apresentarem expressões imediatas na morbimortalidade ${ }^{8}$, porquanto podem demorar anos para se manifestarem em forma de determinadas patologias. De tal modo, a citada autora explicita: "o estresse e a fadiga não matam necessariamente em curto prazo, mas vão minando o organismo pouco a pouco" (SELIGMANN-SILVA, 2011, p. 405). Nesse sentido, estes comentários são elucidativos: "O que hoje não é sintomático pode vir a ser, daqui há cinco anos, daqui há dez anos né, pela qualidade de vida". (entrevista 6); "[...] a gente tem sim, uma relação de adoecimento, mas ela varia na sua intensidade de pessoa para pessoa. Umas afloram logo, outras não”. (entrevista 13).

No caso de docentes assistentes sociais é mister considerar, ainda, os impactos oriundos da feminização desta categoria profissional, pois a lógica capitalista-racista-patriarcal disseminada em nossa sociedade induz maior sobrecarrega às mulheres ao responsabilizá-las, exclusiva ou prioritariamente, pelo trabalho necessário à reprodução de sua própria vida e de seus familiares. Nesse aspecto, a maior parte dessas docentes costuma realizar trabalho doméstico (13), dentre as quais, duas não especificaram a quantidade de tempo destinado a isso e as outras 11 respostas afirmaram que se dedicam a essas atividades, em média, $2 \mathrm{~h} 40 \mathrm{~min}$ por dia, sendo que o menor tempo apontado foi 1 hora e o maior 4 horas diárias. A esse respeito, é ilustrativa a pesquisa realizada por Araújo et al. (2005), a qual evidenciou que os vários problemas de saúde identificados entre docentes participantes do seu estudo foram relatados mais frequentemente entre mulheres (77,9\%).

Em meio a esse contexto de notória influência do trabalho na fragilização da saúde de docentes, foi intrigante constatar que nem sempre os sintomas de adoecimento, de qualquer natureza, são cuidados mediante afastamento do trabalho. Segundo relataram as entrevistadas, quando são acometidas por algum problema de saúde, salvo em situações mais graves/incapacitantes, é comum trabalharem na universidade ou, quando isso não é possível, desenvolvem atividades docentes em casa, tais como as correções de trabalhos, elaboração de artigos, orientações por e-mail ou WhatsApp, dentre outras.

Assim, estando num cargo de gestão, é bem difícil isso, porque por exemplo eu adoeci semana passada, eu fiquei dois dias sem vir, no terceiro eu já vim e estava com febre, por exemplo. E nos dois dias que eu estava em casa eu fiquei [...] tentando acompanhar e resolver coisas. Então, não tem como me desligar, completamente não. (entrevista 1). 
É impressionante, mas a gente não se afasta. [...] A gente faz muito isso! Eu acho que na verdade na maioria dos adoecimentos a gente trabalha doente. [...] Você vai ver como a maioria vai dizer que trabalha doente. Só em situações extremamente graves é que a gente se afasta. (entrevista 16).

Vale ressalvar, conforme explicita uma docente (entrevista 13), que o costume de dar continuidade ao trabalho mesmo acometida por alguma enfermidade não se apresenta como uma solicitação ou exigência da instituição. Em contrapartida, outra entrevistada (entrevista 10) aponta que isso ocasiona, inclusive, subnotificação, pois é comum ocorrerem adoecimentos de menor complexidade, nos quais sequer são encaminhados atestados. Alguns relatos explicitam um aspecto relacionado à particularidade do trabalho docente que ajuda a elucidar a resistência das docentes quanto ao afastamento de suas atividades: a necessidade de reposição de aulas/ conteúdos associada à existência de prazos acadêmicos rígidos, incapazes de se ajustarem à condição individual do(a) professor(a), assim como a busca de evitar sobrecarregar ainda mais os(as) outros(as) docentes. A fala a seguir é elucidativa.

A ideia às vezes, assim, que fica... eu estou querendo reconstruir isso, mas é muito forte uma ideia de que, na docência, não ir piora. Porque a gente tem... a gente trabalha muito com o conteúdo. Então, se eu perco aquele dia de aula, vamos supor, eh... eu vou ter que encontrar um dia pra que aquele conteúdo seja dado, entendeu? [...]. Em geral, se eu percebo que tem um gasinho ainda funcionando, entende? Aquele gasinho assim, eu vou. Eu acho que eu estico muito a corda. (entrevista 15).

Mesmo entre as (três) entrevistadas que não costumam trabalhar quando estão doentes, fica evidente em suas falas que elas se deparam com a recorrência desta prática no âmbito acadêmico, conforme ilustra este fragmento:

Eu já vi colegas estarem numa condição muito difícil e estarem numa mesa de debate. E eu dizer: você está fazendo o que aqui? Eu já vi colegas doentes irem dar aula, estar nas bancas e eu pergunto: meu Deus, porque que essa pessoa está fazendo isso com ela!? Eu não faço! (entrevista 8).

O costume de dar continuidade às atividades acadêmicas mesmo com a saúde fragilizada não é algo recorrente apenas nas IES investigadas. É o que demonstra, por exemplo, uma pesquisa realizada por Barros (2014) com docentes de um curso da Universidade do Estado do Pará, cujos resultados apontam que 71\% dos(as) entrevistados(as) relataram já ter trabalhado doentes, sem recorrer a atestado ou licença médica.

As participantes da nossa pesquisa registram poucos afastamentos do trabalho, motivados, principalmente, por cirurgias, perda da mobilidade devido a fraturas ósseas, problemas circulatórios e depressão. Outro fato que chamou a atenção no tocante aos atestados médicos para afastamentos do trabalho: três comentaram que já estiveram com atestado em mãos e não chegaram a utilizá-lo, pois como era uma situação de reduzida gravidade, continuaram trabalhando - ainda que de forma mais amena — durante o período. Outra relatou ter sugerido ao médico uma redução do tempo de afastamento.

Contrariamente, algumas poucas docentes (três) costumam se afastar do trabalho quando adoecem. Essas, após acumularem demasiado cansaço e desgaste oriundo desse processo, afirmaram que decidiram reduzir o tempo disponibilizado por elas ao trabalho, bem como evidenciaram a necessidade de aproveitarem mais as outras dimensões da vida e intensificarem o autocuidado como forma de fortalecer sua saúde.

Hoje eu não quero trabalhar acima das minhas possibilidades, porque quando chega uma certa idade você não tem a mesma capacidade, a mesma dinâmica que você tinha antes. Quando chega nos cinquenta você não tem a mesma vitalidade né? Embora você tenha interesse, você tenha mais conhecimento, mais habilidade com a forma de tratar as coisas que você faz, mas a gente já vem num processo de... de sobrecarga que faz com que você esgote né? [...] Até meu organismo não aceita mais. (entrevista 4).

As professoras sinalizaram ainda que o adoecimento docente não é algo situado apenas no contexto investigado, mas que se espraia pelos diversos espaços acadêmicos. Desse modo, foi registrada a necessidade de fortalecimento de atividades de prevenção e cuidado com a saúde de docentes, técnicos e estudantes no âmbito das instituições investigadas. 
Além do desgaste oriundo da sobrecarga e adversidades em termos de condições de trabalho, outras falas evidenciaram as determinações do atual contexto societário na fragilização da saúde dos sujeitos. Uma professora assinalou o assédio sofrido atualmente, por docentes de universidades públicas, no que tange à disseminação da ofensiva de culpabilização do(a) trabalhador(a) do serviço público, citando ainda as ameaças de retrocessos na aposentadoria, o desfinanciamento da educação pública, as ofensivas deflagradas para fragilizar os sindicatos, que impõem inseguranças aos trabalhadores(as) e acabam impactando na subjetividade destes(as) trabalhadores(as). (entrevista 6)

Vale destacar, ainda, um comentário que nos instiga a refletir acerca da capacidade/particularidade humana para lidar com os desafios contemporâneos que permeiam o trabalho docente.

[...] o trabalho no capitalismo tem uma dimensão adoecedora, é um solo de competição. Não é que as pessoas queiram competir. Tem uma materialidade que é competitiva, eu reconheço isso. O trabalho intelectual tem uma dimensão do poder, não é? Da competição, do saber como poder. Eu reconheço essas coisas todas, mas eu acho também que há uma fragilidade contemporânea para lidar com os desafios que são inerentes às características desse trabalho. Deu pra entender que são as duas coisas? (entrevista 15).

É notório que na realidade contemporânea tem se explicitado uma tendência à elevação dos índices de adoecimento mental na população e isso tende a se manifestar também entre o segmento docente. A questão do adoecimento da população em geral e dos(as) docentes é uma discussão complexa que envolve inúmeros aspectos, daí a importância da perspectiva de totalidade que norteia este estudo. Nos termos de Pinheiro et al. (2012, p. 940):

[...] o perfil de adoecimento e morte dos trabalhadores resulta da articulação entre os fatores de risco aos quais se expõem como membros de uma comunidade mais geral, acrescidos daqueles aos quais se expõem no trabalho, tornando este adoecimento e o seu reconhecimento pelas instituições públicas cada vez mais complexo.

Vale salientar que, mesmo diante de situações sociais semelhantes, cada ser humano processa de forma singular suas vivências cotidianas em interação com os fatores biológicos que lhes são inerentes e em articulação com as diversas dimensões da sua vida cotidiana e isso se manifesta diferentemente em termos da influência que tais situações exercem ou não na sua condição de saúde. O comentário a seguir aponta nessa direção:

[...] a gente tem colegas muito jovens, mas em função de várias questões, acho que tem muito a ver também com essa... esse ritmo... tem pessoas mais frágeis emocionalmente e fisicamente (entrevista 8).

Por fim, os dados da pesquisa permitem inferir que existe elevada ocorrência de adoecimento entre as docentes, que se deve à interação de inúmeros elementos, entre eles, as condições e o ritmo de trabalho, que apresentam uma importância significativa, uma vez que o trabalho ocupa um lugar central na vida cotidiana.

\section{Considerações finais}

Os dados da pesquisa explicitaram que o trabalho docente é perpassado por sobrecarga constante, trabalho intenso que comumente não chega a ser suspenso em período de férias (pelo menos não totalmente), licença prêmio e nem mesmo durante alguns processos de adoecimento.

Diante do exposto e considerando as múltiplas determinações do processo de saúde-adoecimento humano, consideramos que os dados oriundos deste estudo demonstram que as condições de trabalho docente nas universidades públicas são desgastantes e trazem influxos no adoecimento desses(as) trabalhadores(as), embora, comumente, os nexos entre a vida laboral e a situação de saúde não estejam formalmente estabelecidos e registrados, e/ou nem sempre sejam visibilizados ou mesmo passíveis de constatação por parte das próprias docentes.

Por fim, recomenda-se a elaboração de mais estudos que contemplem outros aspectos que esta pesquisa não se propôs a investigar e contribuam para desvelar relações causais entre trabalho docente e adoecimento, adensando o conhecimento acerca do assunto; bem como a melhoria das condições de trabalho e construção/ 
ampliação de medidas voltadas para a prevenção do adoecimento desses(as) trabalhadores(as). Ademais, é imprescindível apontar que a luta pela garantia de condições de trabalho mais saudáveis deve ter como horizonte a construção de uma nova sociabilidade assentada na emancipação humana e que, assim, potencialize as condições de saúde de todos os sujeitos sociais.

\section{Referências}

ALBUQUERQUE, G. S. C; SILVA, M. J. S. Sobre a saúde, os determinantes da saúde e a determinação social da saúde. Revista Saúde em Debate. Rio de Janeiro, n. 103, v. 38. p. 953-965, 2014. DOI https://doi.org/10.5935/0103-1104.20140082.

ANTUNES, R, PRAUN L. A sociedade dos adoecimentos no trabalho. Serviço Social e Sociedade, São Paulo, n. 123, p. 407-427, jul./set. 2015. DOI https://doi.org/10.1590/0103-1104201611116.

ARAÚJO, T. M.; SENA, I. P.; VIANA, M. A.; ARAÚJO, E. M. Mal-estar docente: avaliação de condições de trabalho e saúde em uma instituição de ensino superior. Revista Baiana Saúde Pública, Salvador, n. 1, v. 29, p. 6-21, jan./jun. 2005.

BARDIN, L. Análise de conteúdo. São Paulo: Edições 70, 2011.

BARROS, C. M. R. O trabalho docente e o processo de adoecimento no curso de educação física da Universidade do Estado do Pará. 2014. 103 f. Dissertação (Mestrado em educação) - Universidade do Estado do Pará, Belém, 2014.

BRASIL. Lei no 8.080, de 19 de setembro de 1990. Dispõe sobre as condições para a promoção, proteção e recuperação da saúde, a organização e o funcionamento dos serviços correspondentes e dá outras providências. Brasília, DF: Diário Oficial da União, 20 set. 1990. FORATTINI, C. D.; LUCENA, C. Adoecimento e sofrimento docente na perspectiva da precarização do trabalho. Laplage em Revista, Sorocaba, n. 2, v. 1, p. 32- 47, maio/ago. 2015. DOI http://dx.doi.org/10.24115/S2446-622020151219p.32-47.

GOUVÊA, L. A. V. N. DE. As condições de trabalho e o adoecimento de professores na agenda de uma entidade sindical. Revista Saúde em Debate. Rio de Janeiro, v. 40, n. 111. p. 206-219, out./dez. 2016. DOI https://doi.org/10.1590/0103-1104201611116.

LEITE, J. L. Produtivismo acadêmico e adoecimento docente: duas faces da mesma moeda. In: FERREIRA, A. V. et al.(org.). Precarização do trabalho e saúde docente nas universidades públicas brasileiras. Fortaleza: EdUECE, 2015. p. 73-78.

LIMA, R. de L. Docência e Serviço Social: condições de trabalho e saúde. Temporalis, v. 16, n. 31, p. 261-279, 2016. Disponível em: https://periodicos.ufes.br/temporalis/article/view/12200/10108. Acesso em: 10 dez. 2020.

MARX, K. O capital: crítica da economia política. Livro I. São Paulo: Bertrand Brasil, 1987.

PINHEIRO, T. M. M. et al. Saúde do trabalhador. In: CAMPOS, G. W. S. et al.(org.). Tratado de Saúde Coletiva. São Paulo: Hucitec, 2012. p. 935-964.

QUEIRÓZ, M. de F. F.; EMILIANO, L. L. Ser docente no Século XXI: o trabalho em uma universidade pública brasileira. Revista Katálysis, Florianópolis, v. 23, n. 3. p. 687-699, set./dez. 2020. DOI https://doi.org/10.1590/1982-02592020v23n3p687.

SADER, E.; GENTILI, P. (org.). Pós-neoliberalismo: As políticas sociais e o Estado democrático. São Paulo: Paz e Terra, 1995. SELIGMANN-SILVA, E. Trabalho e desgaste mental: o direito de ser dono de si mesmo. São Paulo: Cortez; 2011.

\section{Notas}

1 Este processo inclui tanto a relação direta entre o trabalho e a incidência de acidentes, inclusive que resultem em óbito; como também os adoecimentos (físicos e/ou mentais) com nexo laboral, quando se considera doenças e agravos à saúde induzidos/agravados mediante exposição a condições de trabalho prejudiciais à saúde. Nessa perspectiva, Pinheiro et al. (2012), fundamentando-se em Schilling (1984), explicitam que as doenças e agravos à saúde relacionadas ao trabalho podem ser classificadas em três grupos: No grupo I estão as doenças nas quais o trabalho é condição necessária para que ocorram tais agravos. "O grupo II abrange as doenças comuns, que têm sua ocorrência, frequência ou evolução modificadas pela situação de trabalho, como ocorre com o câncer de pele em trabalhadores rurais ou a hipertensão arterial em condutores de ônibus urbanos, entre outras. No grupo III estão os agravos nos quais o trabalho é provocador de um distúrbio latente ou agravador de uma doença ou distúrbio preexistente". (PINHEIRO et al., 2012, p. 940).

2 O projeto foi aprovado pelo Comitê de Ética em Pesquisa da UERN, conforme parecer no 3.147 .284 , de 14 de fevereiro de 2019.

3 "O trabalho, como criador de valores de uso, como trabalho útil, é indispensável à existência humana — quaisquer que sejam as formas de sociedade - é necessidade natural e eterna de efetivar o intercâmbio material entre o homem e a natureza, e, portanto, de manter a vida humana". (MARX, 1987, p. 50).

4 "O capital não tem a menor consideração com a saúde e com a vida do trabalhador, a não ser quando a sociedade o compete a respeitá-las". (MARX, 1987, p. 306). 
5 Trata-se de um conjunto de mecanismos voltados para o enfrentamento de mais um ciclo da reincidente crise estrutural do capital, difundida mundialmente desde meados da década de 1970 e que se instala no contexto brasileiro a partir dos anos 1990. Tais medidas se fundamentam no neoliberalismo, que reeditam a ideias do velho liberalismo, defendendo a não intervenção estatal no social, baseado na perspectiva que o mercado se auto-regula e que a intervenção só trará mais injustiça social, por "premiar" quem não se esforçou para obter seus bens no mercado. Ver particularmente Sader e Gentili (1995).

6 Essa modalidade de gestão, a exemplo da participação nos lucros e resultados (PLR), impulsiona a flexibilização dos salários, a partir do estabelecimento de recompensa pelo esforço e engajamento no alcance das metas, com incremento da intensidade do trabalho e da produtividade; sem, contudo, estipular qualquer compromisso com a preservação da saúde do(a) trabalhador(a) (Antunes, Praun, 2015). Resguardadas as devidas particularidades, sinalizamos que nas universidades vem se praticando estratégia que se assemelha a estas, como é o caso das bolsas de produtividade, por meio das quais é possível obter acréscimo flexível/temporário ao salário, mediante seleção calcada prioritariamente em critérios de produtividade.

7 Ribeiro (apud GOUVÊA, 2016, p. 212) explicita que "as relações sociais do trabalho com a perda da saúde deixaram de ser tão explícitas porque o trabalho contemporâneo tende a 'queimar de dentro para fora' o corpo em trabalho sem que haja combustão visível".

8 O termo morbimortalidade se refere ao conjunto das morbidades (doenças) e inclui também a mortalidade (óbitos) induzidas/ influenciadas/agravadas pelo trabalho.

\section{Iana Vasconcelos}

ianavasconcelos@bol.com.br

Doutora em Ciências da Saúde pela Universidade Federal do Rio Grande do Norte (UFRN)

Professora da Faculdade de Serviço Social da Universidade do Estado do Rio Grande do Norte (UERN)

\section{UERN}

Campus Central, BR 110, KM 48, Rua Prof. Antonio Campos, S/N, Costa e Silva, Mossoró, RN, Brasil. CEP 59.610-090.

\section{Rita de Lourdes de Lima}

rita.pires2@gmail.com

Doutora em Serviço Social pela Universidade Federal de Pernambuco (UFPE)

Professora do Programa de Pós-Graduação em Serviço Social da Universidade Federal do Rio Grande do Norte (UFRN)

\section{UFRN}

Avenida Senador Salgado Filho, S/N, Campus Universitário, Lagoa Nova, Natal, RN, Brasil. CEP:59072-970

\author{
Agradecimentos \\ Agradecemos às professoras que se disponibilizaram a \\ participar deste estudo, cujas contribuições foram fundamentais \\ para o conhecimento da realidade investigada.

\section{Agência financiadora} \\ Não se aplica. \\ Contribuições das autoras \\ Iana Vasconcelos elaborou a concepção do estudo, a produção \\ e análise dos dados e a redação do manuscrito; Rita de Lourdes \\ de Lima participou do planejamento da pesquisa, da análise dos \\ dados, da redação e revisão final do artigo
}

\section{Aprovação por Comitê de Ética}

A pesquisa (CCAE 03227418.2.0000.529) foi aprovada pelo Comitê de Ética em Pesquisa da Universidade do Estado do Rio Grande do Norte, mediante parecer N. 3.147.284, emitido em 14 de fevereiro de 2019. Foi utilizado Termo de Consentimento Livre e Esclarecido.

\section{Consentimento para publicação}

Consentimento das autoras.

Conflito de interesses

Não há conflito de interesses. 